Development and Testing of a 6-Cylinder $\mathrm{HCCl}$ Engine for Distributed Generation

D. L. Flowers, J. Martinez-Frias, F.

Espinosa-Loza, R. Dibble, M. Kristic, A. Bining, Nick Killingsworth

July 13, 2005

Internal Combustin Engine Division of ASME 2005 Fall Technical Conference Ottawa, Canada September 11, 2005 through September 14, 2005 
This document was prepared as an account of work sponsored by an agency of the United States Government. Neither the United States Government nor the University of California nor any of their employees, makes any warranty, express or implied, or assumes any legal liability or responsibility for the accuracy, completeness, or usefulness of any information, apparatus, product, or process disclosed, or represents that its use would not infringe privately owned rights. Reference herein to any specific commercial product, process, or service by trade name, trademark, manufacturer, or otherwise, does not necessarily constitute or imply its endorsement, recommendation, or favoring by the United States Government or the University of California. The views and opinions of authors expressed herein do not necessarily state or reflect those of the United States Government or the University of California, and shall not be used for advertising or product endorsement purposes. 


\title{
Development and Testing of a 6-Cylinder HCCI Engine for Distributed Generation
}

\author{
Daniel L. Flowers, Joel Martinez-Frias, Francisco Espinosa-Loza, \\ Nick Killingsworth, Salvador M. Aceves \\ Lawrence Livermore National Laboratory \\ 7000 East Ave., L-644 \\ Livermore, CA 94551 \\ (925) 422-0529 \\ flowers4@1lnl.gov \\ Robert Dibble \\ Department of Mechanical Engineering \\ University of California \\ 6159 Etcheverry Hall \\ Berkeley, CA 94720 \\ Miroslav Kristic \\ Department of Mechanical and Aeronautical Engineering \\ University of California, San Diego \\ La Jolla, CA 92093 \\ Avtar Bining \\ California Energy Commission \\ Energy Research and Development Division \\ Research and Development Office \\ 1516 - 9th Street, MS-43 \\ Sacramento, CA 95814-5512
}

\begin{abstract}
This paper describes the technical approach for converting a Caterpillar 3406 natural gas spark ignited engine into HCCI mode. The paper describes all stages of the process, starting with a preliminary analysis that determined that the engine can be operated by preheating the intake air with a heat exchanger that recovers energy from the exhaust gases. This heat exchanger plays a dual role, since it is also used for starting the engine. For start-up, the heat exchanger is preheated with a natural gas burner. The engine is therefore started in HCCI mode, avoiding the need to handle the potentially difficult transition from SI or diesel mode to HCCI. The fueling system was modified by replacing the natural gas carburetor with a liquid petroleum gas (LPG) carburetor. This modification sets an upper limit for the equivalence ratio at $\square-0.4$, which is ideal for HCCI operation and guarantees that the engine will not fail due to knock. Equivalence ratio can be reduced below 0.4 for low load operation with an electronic control valve. Intake boosting has been a challenge, as commercially available turbochargers are not a good match for the engine, due to the low HCCI exhaust temperature. Commercial introduction of HCCI engines for stationary power will therefore require the development of turbochargers designed specifically
\end{abstract}


for this mode of operation. Considering that no appropriate off-the-shelf turbocharger for HCCI engines exists at this time, we are investigating mechanical supercharging options, which will deliver the required boost pressure ( 3 bar absolute intake) at the expense of some reduction in the output power and efficiency. An appropriate turbocharger can later be installed for improved performance when it becomes available or when a custom turbocharger is developed. The engine is now running in HCCI mode and producing power in an essentially naturally aspirated mode. Current work focuses on developing an automatic controller for obtaining consistent combustion in the 6 cylinders. The engine will then be tested for 1000 hours to demonstrate durability. This paper presents intermediate progress towards development of an HCCI engine for stationary power generation and next steps towards achieving the project goals.

\section{Introduction}

HCCI (homogeneous charge compression ignition) engines have recently emerged as an alternative prime mover for transportation and stationary applications. Automobile and engine manufacturers are interested in HCCI engines due to their potential for high efficiency and low emissions. HCCI combustion is fundamentally different than combustion in spark-ignited (SI) engines and diesel engines. HCCI combustion is a thermal autoignition of a premixed fuel-air mixture, with no flame propagation (as in SI engines) or mixing-controlled combustion (as in diesel engines) [1]. HCCI engines can run extremely lean (equivalence ratio $\sim 0.4$ ) or very dilute (residual gas fraction $\sim 0.6$ ). In either case, the combustion temperature is low enough that the engine produces extremely low $\mathrm{NO}_{\mathrm{x}}$ emissions (a few parts per million, ppm) with no need for aftertreatment. Lean, premixed combustion also results in near zero particulate matter emissions. Finally, HCCI engines do not require spark plugs or a three-way catalyst, and are therefore expected to have lower maintenance costs than SI engines. In summary, HCCI engines have a combination of characteristics that may make them desirable for power generation, including high brake thermal efficiency, low $\mathrm{NO}_{\mathrm{x}}$ emissions and low maintenance requirements.

HCCI engines do present some technical challenges that have so far kept them from widespread commercialization. The main hurdles are combustion timing control, low specific power output, high emissions of hydrocarbon (HC) and carbon monoxide (CO), and difficulty to start when cold [1]. These are formidable technical challenges for transportation applications, due to the fast transients required to meet the road load and due to the size restrictions inside a vehicle. However, for stationary applications, these issues are not nearly as challenging, because a stationary engine runs predominantly at a constant speed and the load changes relatively slowly. Under these conditions, combustion control becomes much more tractable. External components (e.g. a burner and heat exchanger for starting the engine [2]) can easily be installed in stationary engines, since size restrictions are typically not as strict as for transportation applications.

In this paper we describe the process for converting a 6-cylinder heavy duty SI engine into HCCI mode. The paper presents all the stages of the conversion process, starting with basic analysis and then describing all the necessary modifications in the different engine systems, including the thermal management and continuing with the starting system, the fueling system, the boosting system and the controls. This research and development project is part of the California Energy Commission (CEC) Advanced Reciprocating Internal Combustion Engine (ARICE) Program and has the goal of developing a $45 \%$ efficient engines with $0.02 \mathrm{~g} / \mathrm{kWh} \mathrm{NO}_{\mathrm{x}}$ and $0.026 \mathrm{~g} / \mathrm{kWh} \mathrm{CO}$, 
at $\square \$ 700 / \mathrm{kW}$ cost and $\geq 10,000$ hours B10 durability ( $\geq 45,000$ hours between major overhauls). This specific project focuses primarily on research and development towards meeting the performance and emissions targets of the CEC ARICE program, with a planned 1000 hours of testing to demonstrate a level of durability. Demonstration of the ability of this technology to meet the full durability is left to future work, and achievement of the cost goal will need to be demonstrated by the manufacturer and retailer.

\section{The Engine}

We are converting a Caterpillar 3406 Natural Gas Spark Ignited engine to HCCI mode. The main characteristics of this engine are listed in Table $1[3,4]$. The engine is rated at $190 \mathrm{~kW}$, with 6 cylinders, 14.6 liters displacement and 10:3:1 compression ratio. The engine efficiency is low (29.5\% at full load) and it produces high emissions. The purpose of this project is to improve the efficiency and reduce the emissions of the engine through conversion to HCCI. Power rating should remain reasonable $(\sim 200 \mathrm{~kW})$. The unit is intended as a prototype but should utilize only production viable hardware and technology. Durability of the unit will be demonstrated through a 1000 hour operation schedule during which efficiency and emissions will be tracked and system failure modes will be determined.

The first modification to the engine was to replace the stock pistons with pistons typically used in the diesel version of the Caterpillar 3406, with higher compression ratio (16:1) and shallow bowl geometry. This modification was necessary to improve the thermal efficiency of the engine and to promote fuel ignition. Spark plugs were also removed, and now pressure sensors (one for each cylinder) occupy the spark plug holes. Other modifications were conducted in all the major engine systems and these are described in the appropriate sections of the paper.

\section{Analysis}

We have conducted detailed analysis of Caterpillar 3406 operation in HCCI mode. The analysis has been described in a previous publication [5] and uses a detailed chemical kinetics code [6] for predicting HCCI ignition, efficiency and emissions, along with thermodynamic models for analysis of other system components (turbine, compressor and heat exchangers). The analysis effort focused on determining whether HCCI combustion can be achieved with natural gas by preheating the intake charge with hot exhaust gases.

The thermal management system for the HCCI engine is shown in Figure 1. Intake air and fuel first circulate through the compressor and then through a preheater and an intercooler. The preheater and the intercooler are not expected to work simultaneously (i.e., if the operating conditions require the use of the preheater, then the intercooler is by-passed). The charge then circulates into the engine, where it ignites by compression. Engine exhaust runs through an oxidizing catalyst, where the $\mathrm{HC}$ and $\mathrm{CO}$ emissions are burned with the available oxygen. Exhaust is then routed through the turbine, and finally through the recuperator.

Four system parameters (equivalence ratio, intake pressure and effectiveness of preheater and intercooler) are tuned to obtain satisfactory combustion at all operating conditions. The results show that HCCI combustion can be achieved for all the operating range, from idle to peak 
power. Low and mid load operation (up to $150 \mathrm{~kW}$ ) requires the use of the preheater. Peak power $(150-200 \mathrm{~kW})$ requires the use of the intercooler. The results of the analysis indicate that the strategy of preheating the intake charge with exhaust gases does result in satisfactory HCCI combustion. The results also indicate that the $\mathrm{NOx}, \mathrm{HC}$ and $\mathrm{CO}$ emissions targets are achievable. The model predicts $203 \mathrm{~kW}$ peak power and 42\% maximum efficiency, which is lower than the program target (45\%), but considerably higher than the typical efficiency of stoichiometric spark ignited engines, which represent the only existing alternative to HCCI for meeting the very strict program goals for NOx emissions [7].

\section{The Thermal Management System}

The experimental engine was equipped with a thermal management system that follows closely the configuration of Figure 1, which was analytically evaluated and is expected to yield appropriate HCCI combustion. The configuration of Figure 1 was only slightly modified for the experimental engine: the preheater and the intercooler are now in parallel (Figure 2) instead of being in series (Figure 1). The parallel configuration was selected because it has a faster response; since the charge temperature can be quickly controlled by blending varying amounts of the hot and cold streams. In addition to this, the parallel configuration makes it possible to independently control the intake temperature of each cylinder. This is necessary to obtain optimum combustion timing in all cylinders, as differences in charge temperature between cylinders can result in considerable cylinder to cylinder variation in ignition timing. Balancing combustion between cylinders in HCCI engines is an important challenge and is further discussed in the Controls section of this paper.

Figure 3 shows a picture of the thermal management system for the engine. The recuperator is a high temperature heat exchanger, originally designed as a gas turbine recuperator. All the intake lines (except for those in the cold intake stream) have been insulated.

\section{The Starting System}

HCCI engines are often difficult to start. At cold start, the compressed-gas temperature in an HCCI engine is reduced because the charge receives no preheating from the intake manifold and the compressed charge is rapidly cooled by heat transfer to the cold combustion chamber walls. Without some compensating mechanism, the low compressed-charge temperatures could prevent an HCCI engine from firing. A common approach has been to start the engine in spark-ignition mode or diesel mode and transition to HCCI mode after warm-up. However, successful transition typically requires advanced engines equipped with variable compression ratio (VCR) or variable valve timing (VVT), which may be expensive or difficult to implement for heavy duty engines. In practice operation in SI mode requires equivalence ratio of $0.6-0.65$ or greater [8], which is high enough to damage the engine if thermal autoignition or knock occurs during the transition.

Instead of attempting to start the engine in SI mode and transition to HCCI mode, we used a brand new approach: start the engine directly in HCCI mode by preheating the intake with a gas fired burner. This was easy to implement by adding a burner to the preheater (Figure 3 ). The burner is run for a period of time (30 minutes) until the preheater reaches a high temperature $\left(300^{\circ} \mathrm{C}\right)$. At this condition, running the intake charge through the preheater while simultaneously 
spinning the engine with an air starter is enough to achieve HCCI ignition. After ignition, combustion is self sustaining and the burner can be turned off, as the intake gases are heated by the hot exhaust. The burner is a source of emissions and a consumer of fuel, and as such in a practical deployment of an HCCI engine for stationary power generation this would have to be considered as a contributor to the overall system emissions and fuel consumption.

\section{The Fueling System}

The fueling system presents several challenges, because HCCI combustion is extremely sensitive to equivalence ratio. Just a few cycles of $\mathrm{HCCI}$ combustion at high equivalence ratio $(\square>0.5)$ are enough to cause physical damage to the engine. Therefore, the fueling system has to guarantee that no equivalence ratio excursions will occur beyond a "safe" equivalence ratio $(\square-0.45)$ under any circumstances. It may also be desirable to run at low equivalence ratio for low load operation.

These difficult requirements were met with a novel solution: the stock carburetor tuned for natural gas was replaced with a carburetor tuned for liquid petroleum gas (LPG). Considering that the average composition of natural gas is approximately $\mathrm{C}_{1.2} \mathrm{H}_{3.5}$ and the average composition of $\mathrm{LPG}$ is $\mathrm{C}_{3.5} \mathrm{H}_{8.5}$, a carburetor tuned for operating at equivalence ratio 0.9 on LPG will run at $\square-0.3-0.4$ when fueled with natural gas. This is ideal for HCCI, as the carburetor is quite efficient at maintaining the established equivalence ratio. The equivalence ratio is reduced below 0.4 with an electronic control valve that reduces the pressure in the natural gas line (Figure 4).

\section{The Boosting System}

HCCI engines operate at low equivalence ratio $(\square \leq 0.45)$ to avoid damage due to knock. This high level of fuel dilution results in low power output, and intake boosting ( 3 bar absolute pressure) is necessary to obtain appropriate levels of power ( 10 bar BMEP or more). Intake charge boosting was therefore the subject of a detailed analysis based on the WAVE 1dimensional compressible fluid dynamics code [9].

The engine is delivered with a turbocharger. However, the engine was designed to run in sparkignited mode at high equivalence ratio $(\sim 1)$ and with low compression ratio (10.3:1). It is therefore expected that the stock turbocharger will not be appropriate for HCCI operation. This was verified with WAVE, as it was determined that the existing turbocharger would only provide 1.2-1.3 pressure ratio across the compressor, down from 1.8-2 that is available in SI mode. This pressure ratio is clearly not enough to obtain the power level required for this application. Additional turbocharging/supercharging is required.

Five turbochargers were evaluated for application to this engine. These are Honeywell, BorgWarner, Turbonetics, Holset, and a custom Holset turbocharger used at the Lund Institute of Technology. The results of the analysis indicate that none of the commercially available turbochargers delivers the desired performance. The best performing turbocharger is the Lund Holset custom turbocharger, which is not commercially available. The analysis shows that the Lund turbocharger results in $146 \mathrm{~kW}$ and $31 \%$ brake thermal efficiency (BTE). The small nozzle 
area of the prototype turbine resulted in a relative high turbine speed $(\sim 96,000 \mathrm{rpm})$ which enables the compressor to produce boost and the engine to make power. Availability of this option is an issue, as the maps for the Holset turbine were unavailable. Discussions with Lund Institute of Technology indicate that the turbine was a prototype unit for a diesel program.

Looking for a better off the shelf option for the HCCI engine, the WAVE analysis was turned to superchargers. The results are summarized in Figure 4. This figure shows color contours (and solid lines) of engine brake power in $\mathrm{kW}$, as a function of supercharger aerodynamic efficiency and boost pressure. The figure also includes dotted lines showing brake thermal efficiency and dashed lines with peak cylinder pressure. Figure 5 shows that for typical centrifugal supercharger efficiencies ( $\sim 70 \%$ peak efficiency, aerodynamic gear), it appears that $\sim 145 \mathrm{~kW}$ is obtainable with $25.5 \%$ BTE, 170 bar maximum cylinder pressure and 3.1 bar boost pressure. Increasing boost pressure above 3.1 bar can generate slightly more power; however, this increase occurs at the expense of peak cylinder pressure and BTE. For typical roots blower style \& twin screw supercharger efficiencies ( $\sim 60 \%$ peak efficiency), it appears that $\sim 130 \mathrm{~kW}$ is obtainable with a BTE of $\sim 23 \%$, a maximum cylinder pressure of $\sim 170$ bar and a boost pressure of $\sim 3.1$ bar.

The performance offered by typical superchargers is well below the $200 \mathrm{~kW}, 45 \%$ BTE program targets due to the shaft power requirements of the supercharger. Increasing supercharger efficiencies would improve the performance of the engine. However, even a 100\% aerodynamic efficiency supercharger would be limited by peak cylinder pressure to $\sim 180 \mathrm{~kW}$ and $\sim 31 \%$ BTE.

Based on the results of the WAVE analysis a custom supercharger was selected from Vortech Engineering (Model V24XC), which achieves approximately 70\% isentropic efficiency for 3:1 pressure ratio at 55,000 RPM. The supercharger was recently purchased and is being installed on the engine. The stock turbocharger is being kept in the system to provide additional boost.

The results of this analysis indicate that the HCCI engine will be challenged to meet the ARICE efficiency and power targets due to the lack of an appropriate turbocharger. However, it is considered that the project is still a significant step toward the commercialization of HCCI engines, because any company interested in commercializing the technology can easily conduct the necessary work for designing and building a turbocharger that is well matched for this application, considerably increasing the efficiency and power output of the system.

\section{The Control System}

It is typically considered that combustion control is the most challenging problem for widespread commercialization of HCCI engines. The HCCI process gives up two important control aspects: 1) the timing of the start of ignition is not directly controlled by any external event such as the beginning of injection in the standard diesel engine or the sparking of the spark plug in the SI engine, and 2) the heat release rate is not controlled by either the rate and duration of the fuel injection process as in the diesel engine or by the finite turbulent flame propagation time in the SI engine. Instead, HCCI ignition is determined by the charge mixture composition and its temperature history (and to a lesser extent, its pressure history). Changing the power output of an HCCI engine requires a change in the fueling rate and, hence, the charge mixture. As a result, the temperature history must be adjusted to maintain proper combustion timing. Similarly, changing 
the engine speed changes the amount of time for the autoignition chemistry to occur relative to the piston motion. Again, the temperature history of the mixture must be adjusted to compensate. These control issues become particularly challenging during rapid transients.

Multi-cylinder engines pose an additional challenge, since there are always small cylinder to cylinder differences in charge pressure and temperature at intake valve closing, due to differences in volumetric efficiency or coolant temperature. In addition to this, there may be differences in compression ratio between cylinders due to geometric tolerances. These differences are small enough to be negligible in SI and diesel engines. However, HCCI combustion is controlled by thermal autoignition, and is extremely sensitive to temperature. A very small temperature difference can result in a considerable difference in ignition timing. It is therefore necessary to develop a controller that can detect cylinder to cylinder differences in ignition timing and adjust conditions in the individual cylinders so that optimum combustion timing can be achieved in all cylinders under all operating conditions.

Several potential control methods have been proposed to provide the compensation required for changes in speed and load. These include varying the amount of hot EGR introduced into the incoming charge, using a fuel additive to enhance ignition, using a variable compression ratio (VCR) mechanism to alter TDC temperatures, and using variable valve timing (VVT) to change the effective compression ratio and/or the amount of hot residual retained in the cylinder. VVT appears most promising for transportation applications, because its time response could be made sufficiently fast to handle rapid transients.

For stationary applications, HCCI combustion control is not nearly as challenging, because a stationary engine runs predominantly at a constant speed and the load changes relatively slowly. Under these conditions, combustion control becomes much more tractable, and can be accomplished without advanced engine technology such as VVT or VCR. In this application, combustion control is achieved by blending hot and cold intake with control valves. This control system has the additional advantage of being able to independently regulate the intake temperature of each cylinder, to obtain optimum ignition timing in all cylinders (Figures 6 and 7).

The mixing valves are computer controlled. A real-time control system based on Labview's realtime software is used. This system utilizes a dedicated PC running on the Labview real-time operating system as the target, which allows deterministic closed-loop control. Control algorithms can then be easily developed on a host computer connected to the target PC via an Ethernet connection and downloaded onto the target PC for implementation. The control algorithm computes the combustion timing based on the pressure signal from each cylinder. The valve position is then scheduled by the control algorithm to yield the desired combustion timing. The hardware side of this control system consists of an electric motor teamed with a rotary position sensor per each cylinder to control the valve position. The control system inputs consist of pressure signals from each cylinder in conjunction with the output from a crankshaft encoder. The electric motors and sensors necessary for actuation of the valves have been recently purchased and are being installed. This will allow the development and implementation of efficient and robust control strategies on the HCCI engine. 


\section{Engine Testing and Operation}

The engine has been running in HCCI mode for the last year, even without the supercharger and without the computerized controller. While closed loop feedback control offers the greatest flexibility, cylinder pressure balancing can be achieved reasonably by passive tuning of cylinderby-cylinder mixing valves. Figure 8(a) shows in-cylinder pressure traces for engine operation with no cylinder-by cylinder-balancing, all cylinder receiving fuel-air mixture only from the hot reservoir. Clearly, the combustion phasing is not well matched for all cylinders. This imbalance can lead to undesirable occurrences, such as greater propensity for misfire of later firing cylinders when a small change in intake parameters occurs, such as slight variation in load or outside air temperature.

Figure 8(b) shows the effect of adjustment of cylinder one on the pressure traces of the remaining cylinders. The intake temperature of cylinder one is adjusted by blending cold and hot mixture with the mixing tee assembly. This reduces the charge temperature on the most advanced cylinder (cylinder one), effectively adjusting combustion timing for this cylinder. It is important to note that the other cylinders are not noticeably effected by the adjustment of cylinder one. Thus the mixing tee assembly achieves the goal of independent control of combustion timing on a cylinder-by-cylinder basis. Figure 9 shows the result of adjusting all cylinders to achieve well balanced combustion timing for the 6-cylinder engine operating naturally aspirated at equivalence ratio of 0.35 generating power to support an electrical load of $40 \mathrm{~kW}$.

\section{Ongoing and Future Work}

Much progress has been made in this project, but details remain before the 1000 hour durability test is conducted. The key remaining tasks are: Install and test supercharger, Implement software and actuators for fully automated engine control, and Transition technology to a manufacturer or assembler through partnership and licensing. Once the project is complete, we plan to use the engine as a fully instrumented test bed for performance studies of HCCI combustion. Some ideas that may be pursued in the future (beyond the scope of this current project) include the following:

1. HCCI engines for cogeneration: Despite its multiple benefits as an energy saving technology, combined heat and power (CHP) has achieved extremely small market penetration. We have identified HCCI as a technology that will considerably improve fuel utilization efficiency while providing unmatched flexibility in the operating temperatures. At the same time, the technology has potential to meet the very strict CARB 2007 NOx emissions standards and be inexpensive to buy and operate [7].

2. HCCI combustion of wet ethanol: The ethanol fuel industry exists only due to federal government subsidies, and many researchers have determined that making ethanol fuel typically consumes more energy (fertilizers, tractors and processing) than can be obtained from burning the ethanol. We have identified HCCI as a technology that can considerably improve the overall 
energy balance and the economics of ethanol, making the ethanol industry profitable without the need of federal subsidies. HCCI engines are intrinsically fuel flexible, and capable of running on low quality marginal fuels. Our recent analysis indicates that HCCI engines can run on ethanol that contains extremely high fractions of water (perhaps up to $70 \%$ by volume). Use of wet ethanol directly as a fuel for transportation and power generation avoids the need for distilling and dehydrating the ethanol. Considering that distillation and dehydration are the most energy intensive steps in the ethanol cycle, running on wet ethanol can substantially improve the energy balance of this biofuel. HCCI will finally enable ethanol to deliver on its promise of clean, renewable and economic fuel [10].

3. Basic research on HCCI control: The HCCI engine is an ideal test bed for testing control systems for inexpensive and robust combustion control in multi-cylinder engines. We will employ various linear and nonlinear control methodologies to develop control algorithms. Specifically, one method we will use is extremum seeking control to provide online optimization of the engine efficiency and emissions.

\section{Conclusions}

This paper describes the technical approach for converting a Caterpillar 3406 natural gas spark ignited engine into HCCI mode. All major engine systems have been modified to obtain good performance and low emissions.

- A thermal management system was designed and built based on analysis results. The system consists of a preheater and an intercooler connected in parallel. Fresh charge is circulated through either heat exchanger and then blended to obtain appropriate combustion. This system also allows for cylinder by cylinder control of intake temperature.

- The engine is started in HCCI mode by running a natural gas fueled combustor that heats the preheater. The intake gases are then circulated through the hot preheater, reaching a high enough temperature for HCCI ignition to occur. Once combustion starts, it is selfsustaining, and therefore the burner can be turned off quickly after ignition.

- The fueling system was modified by replacing the stock natural gas carburetor by a carburetor designed for liquid petroleum gas. This change adjusts the equivalence ratio to the value desired for HCCI combustion $(\square \sim 0.4)$, and eliminates the risk of overfueling that may damage the engine.

- Selection of a turbocharger caused problems, as the low temperature exhaust in HCCI engines makes commercially available turbochargers inappropriate for HCCI operation. Instead, a supercharger was selected, at the expense of reduced power output and efficiency.

- A real-time control system is being implemented and will allow the development of control algorithms for HCCI engine control. The control system activates blending 
valves between hot and cold intake streams to obtain the appropriate charge temperature for optimum ignition timing in all cylinders.

- The engine has been running in HCCI mode for a year. Good and consistent combustion timing is obtained in all cylinders. High power operation has not been possible because the supercharger has not been installed. The engine has delivered $50 \mathrm{~kW}$ with atmospheric intake. Efficiency and power targets are unlikely to be met due to the lack of an appropriate turbocharger. However, reasonable values are expected with the current design ( $145 \mathrm{~kW}$ is obtainable with $25.5 \%$ brake thermal efficiency). We anticipate meeting all the strict emissions targets set by the ARICE program.

- We envision multiple applications for the engine beyond the current contract. Future applications include testing performance of the HCCI engine for cogeneration, running the engine on wet ethanol for improving the energy balance of ethanol manufacture, and using the engine as a test bed for multi-cylinder HCCI control experiments.

\section{Acknowledgments}

This project is funded by the California Energy Commission, Advanced Reciprocating Internal Combustion Engine (ARICE) Program. This work was performed under the auspices of the U. S. Department of Energy by the University of California, Lawrence Livermore National Laboratory under Contract No.W-7405-Eng-48.

\section{References}

1. Epping, K., Aceves, S.M., Bechtold, R.L., and Dec, J.E., 2002, “The Potential of HCCI Combustion for High Efficiency and Low Emissions," SAE Paper 2002-01-1923.

2. Martinez-Frias, J., Aceves, S.M., Flowers, D., Smith, J.R., and Dibble, R., 2000, "HCCI Engine Control by Thermal Management," SAE Paper 2000-01-2869.

3. Caterpillar Engine Company, "Gas Generator Set," LEHE143-02 (03-02), 2001.

4. Caterpillar Engine Company, "G3406 TA: Gas Engine Technical Data," DM5440-00, June 2001.

5. Martinez-Frias, J., Flowers, D., Aceves, S.M., Espinosa-Loza, F., and Dibble, R., Thermal Management for 6-Cylinder HCCI Engine: Low Cost, High Efficiency, UltraLow NOx Power Generation, Paper ICEF2004-930, Proceedings of the 2004 Fall Technical Conference, ASME Internal Combustion Engine Division, October 2004.

6. Kee, R.J., Rupley, F.M., Meeks, E., and Miller, J.A., 1996, “CHEMKIN III: A FORTRAN Chemical Kinetics Package for the Analysis of Gas-Phase Chemical and Plasma Kinetics," Sandia National Laboratories Report SAND96-8216, Livermore, CA.

7. Aceves, S. M., Martinez-Frias, J., and Reistad, G. M., 2004 "Analysis of Homogeneous Charge Compression Ignition (HCCI) Engines for Cogeneration Applications," Paper IMECE 2004-62371, Proceedings of the ASME International Mechanical Engineering Congress \& Exposition, Anaheim, CA.

8. Flynn, P. F., Hunter, G. L., Farrell, L.A., Durrett, R. P., Akinyemi, O. C., Westbrook, C. K. and Pitz, W. J., "The Inevitability of Engine-Out Nox Emissions from Spark-Ignition and Diesel Engines," Proceedings of the Combustion Institute, Vol 28, 2000. 
9. WAVE, Ricardo Software, website: "http://www.software.ricardo.com/products/wave" 10. Martinez-Frias, J., Aceves, S. M., Flowers, D., 2005, "Improving Ethanol Life Cycle Energy Efficiency by Direct Combustion of Wet Ethanol in HCCI engines," Proceedings of the ASME International Mechanical Engineering Congress \& Exposition, Orlando, FL. 
Table 1 - Summary of important performance specifications for base engine, a natural gas 3406 generator set operating on natural gas $[3,4]$.

\begin{tabular}{|l|l|}
\hline Performance Parameters & \\
\hline Power rating (Continuous Duty) & $190 \mathrm{~kW}$ \\
\hline Number of cylinders & 6 \\
\hline Displacement & $14.6 \mathrm{Liters}$ \\
\hline Bore & $137 \mathrm{~mm}$ \\
\hline Stroke & $164 \mathrm{~mm}$ \\
\hline Compression Ratio & $10.3: 1$ \\
\hline Fuel Consumption @ 100\% Load & $64 \mathrm{~N}-\mathrm{m}^{3} / \mathrm{hr}$ \\
\hline Engine efficiency @ 100\% Load & $29.5 \%$ \\
\hline NOx emission & $19.7 \mathrm{~g} / \mathrm{bhp}-\mathrm{hr}$ \\
\hline CO & $1 \mathrm{~g} / \mathrm{bhp}-\mathrm{hr}$ \\
\hline HC (Total) & $4.2 \mathrm{~g} / \mathrm{bhp}-\mathrm{hr}$ \\
\hline HC (Non-methane) & $0.63 \mathrm{~g} / \mathrm{bhp}-\mathrm{hr}$ \\
\hline Aspiration & Turbocharged-Aftercooled \\
\hline Package Dimensions & \\
\hline Length & $4.0 \mathrm{~m}$ \\
\hline Width & $1.4 \mathrm{~m}$ \\
\hline Height & $2.1 \mathrm{~m}$ \\
\hline Mass & $4318 \mathrm{~kg}$ \\
\hline
\end{tabular}




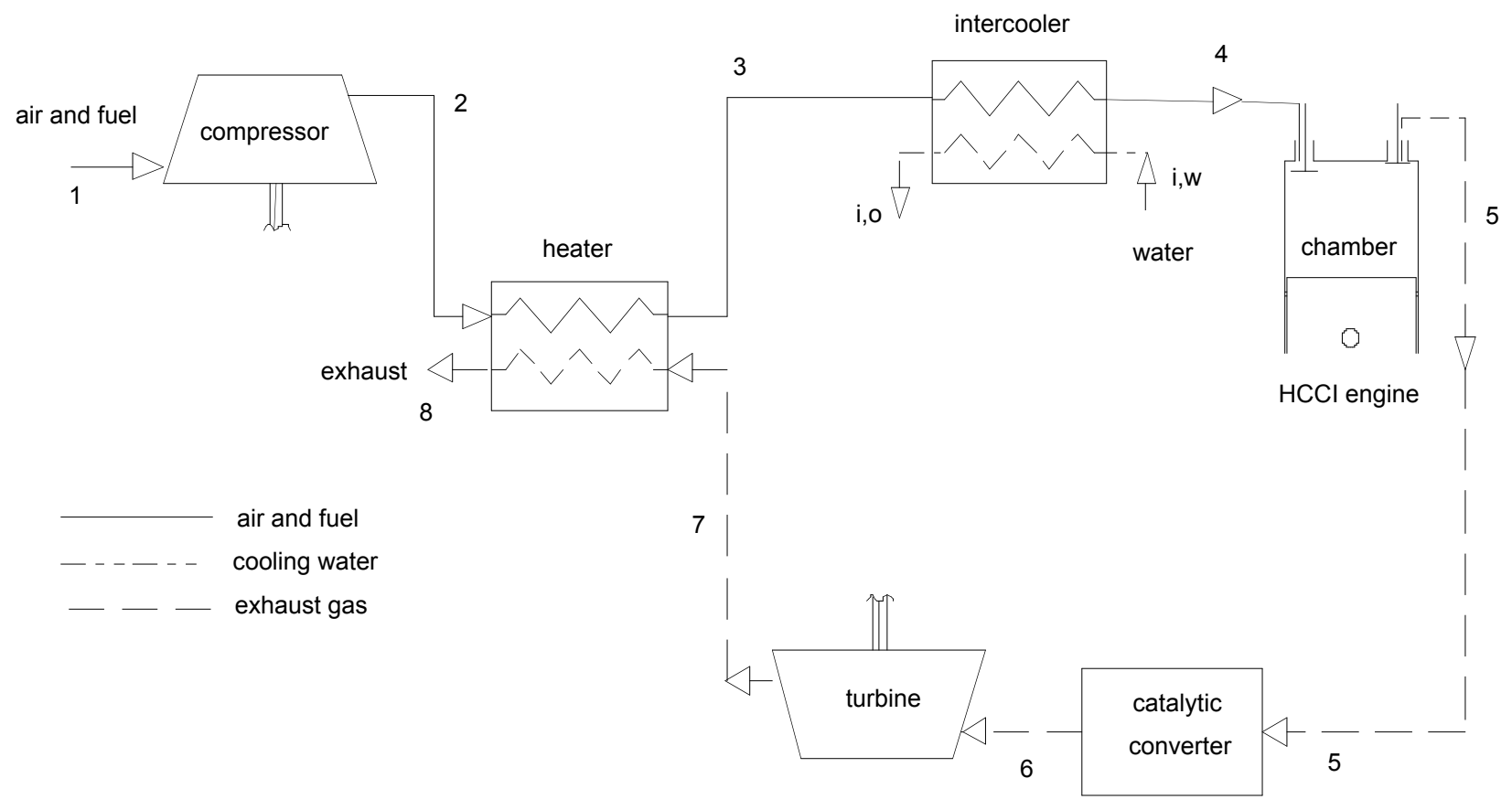

Figure 1. Schematic of the HCCI engine and thermal management system used in the analysis. 


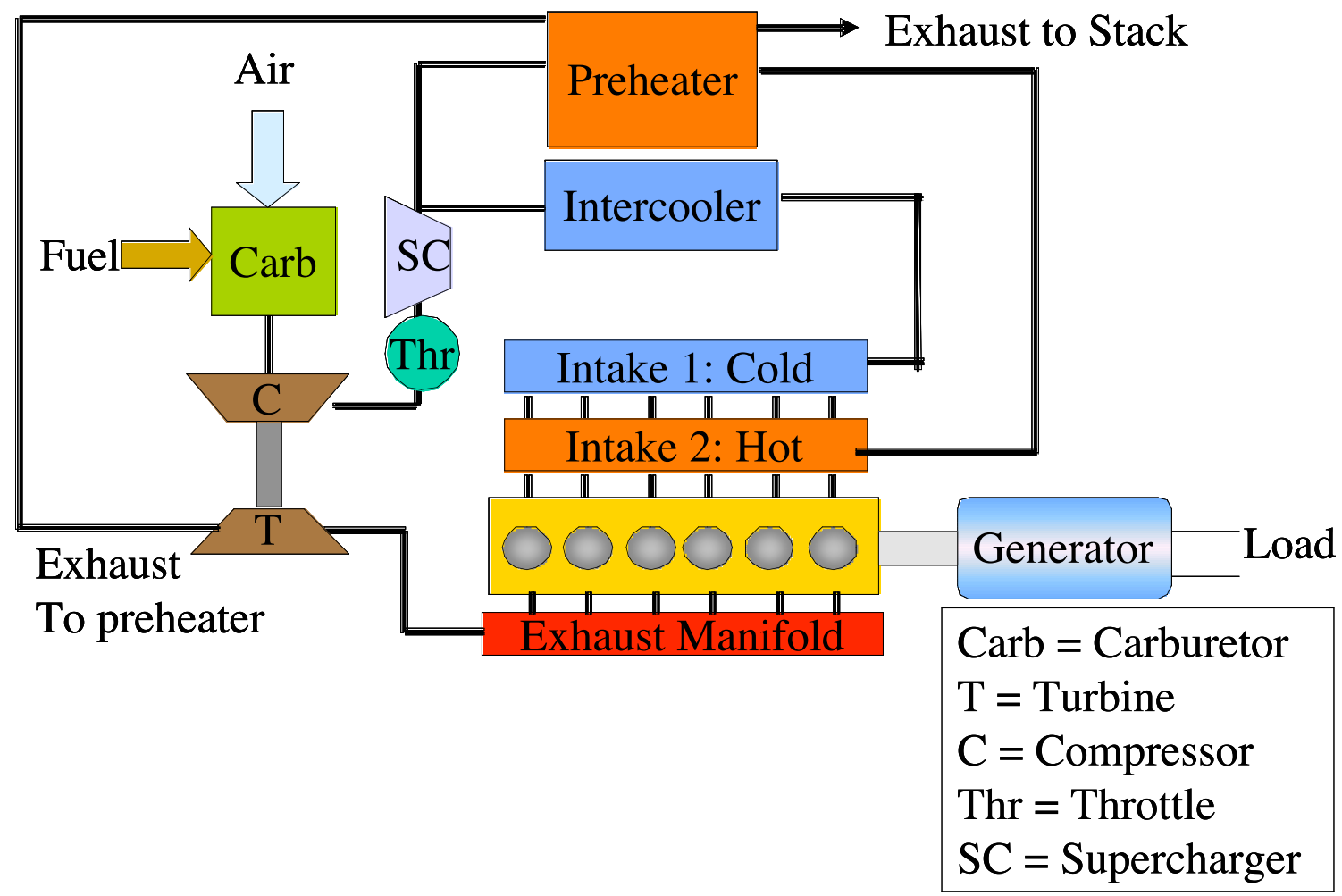

Figure 2. Schematic of the HCCI engine and thermal management system used in the experiment. 


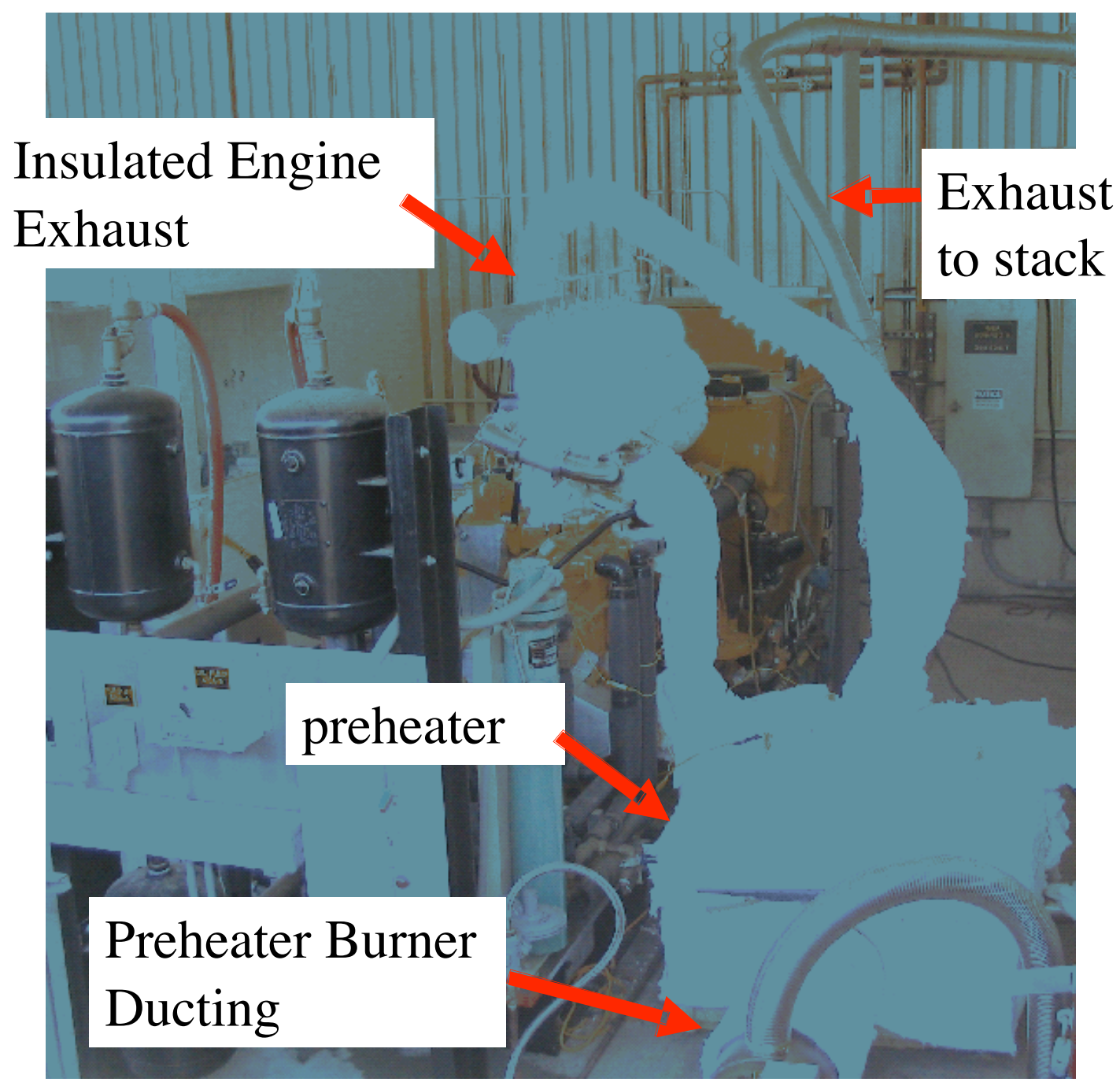

Figure 3. Picture of the engine showing the main components of the thermal management system. 


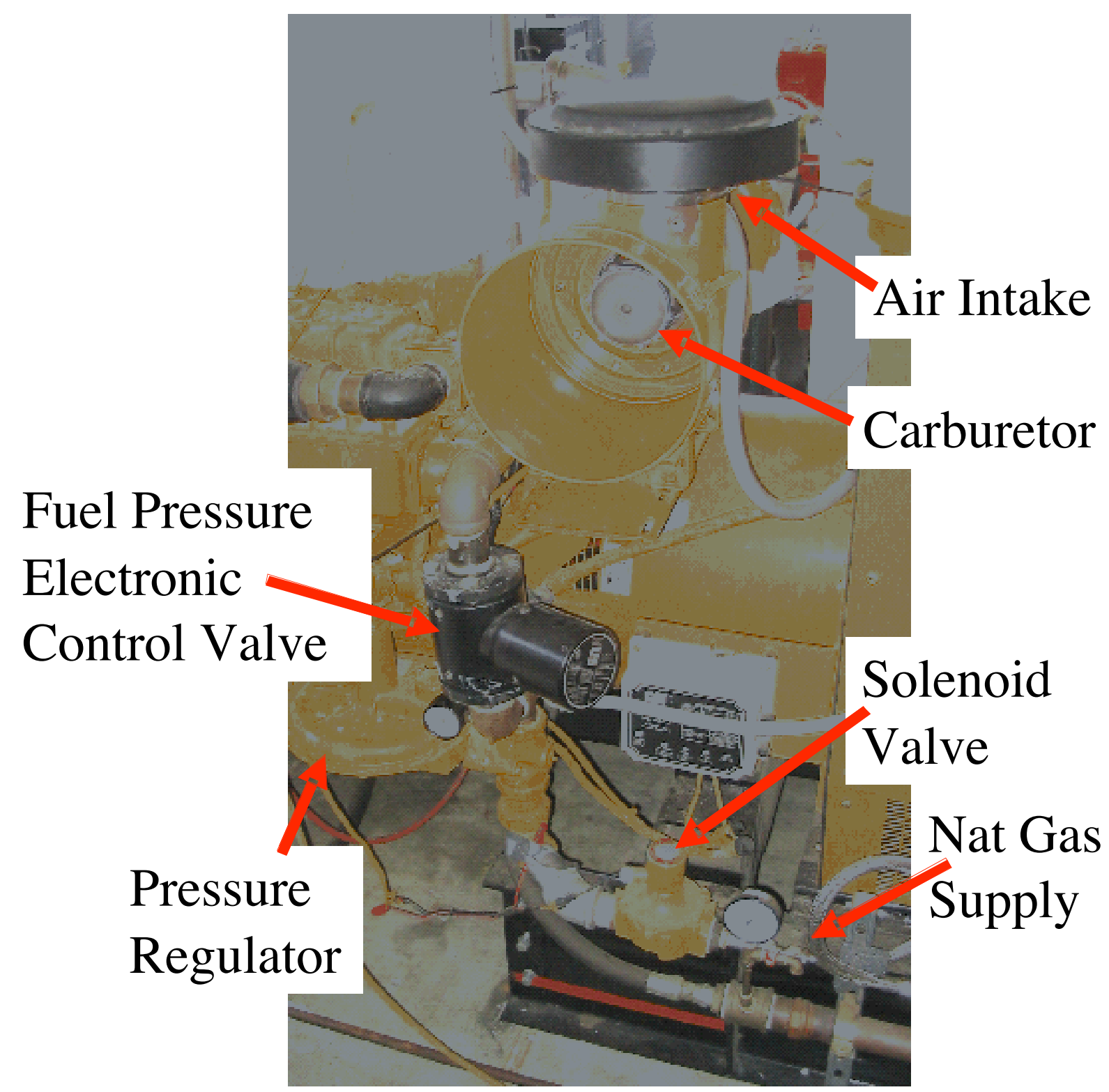

Figure 4. Engine picture showing the fueling system components. 


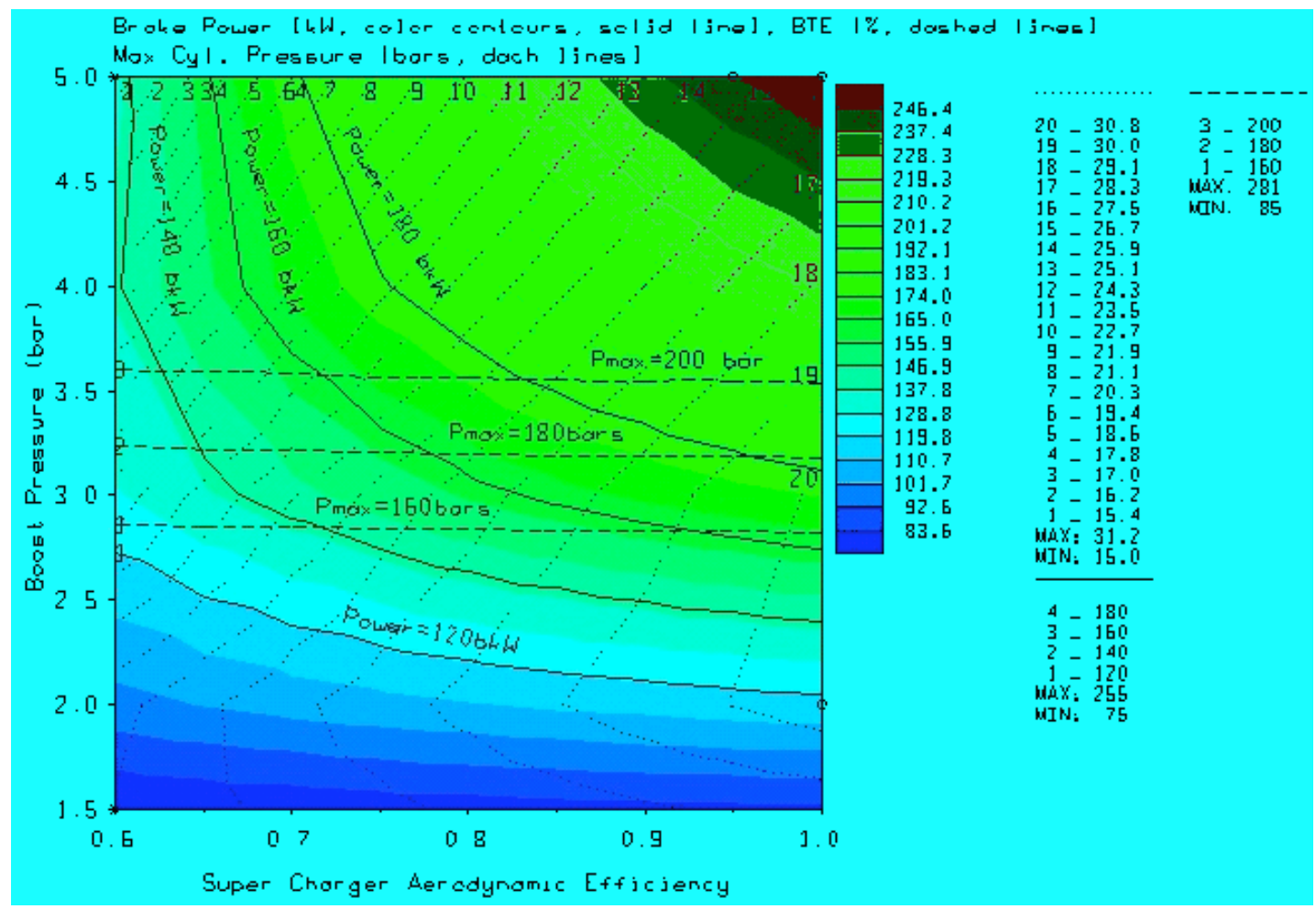

Figure 5. Color contours (and solid lines) of engine brake power in $\mathrm{kW}$, as a function of supercharger aerodynamic efficiency and boost pressure, with dotted lines showing brake thermal efficiency and dashed lines showing peak cylinder pressure. 


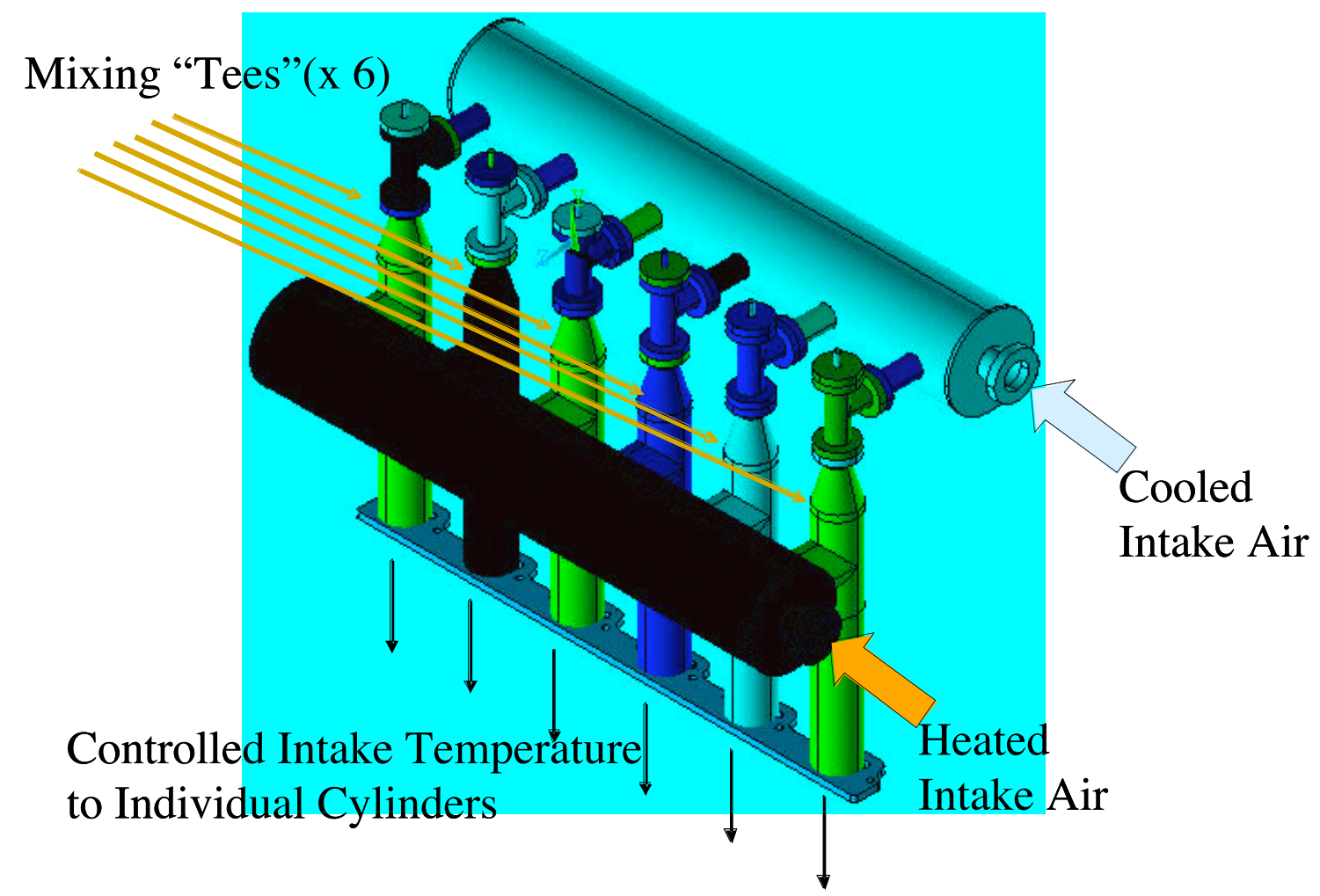

Figure 6 . Schematic of the cylinder by cylinder temperature control. 


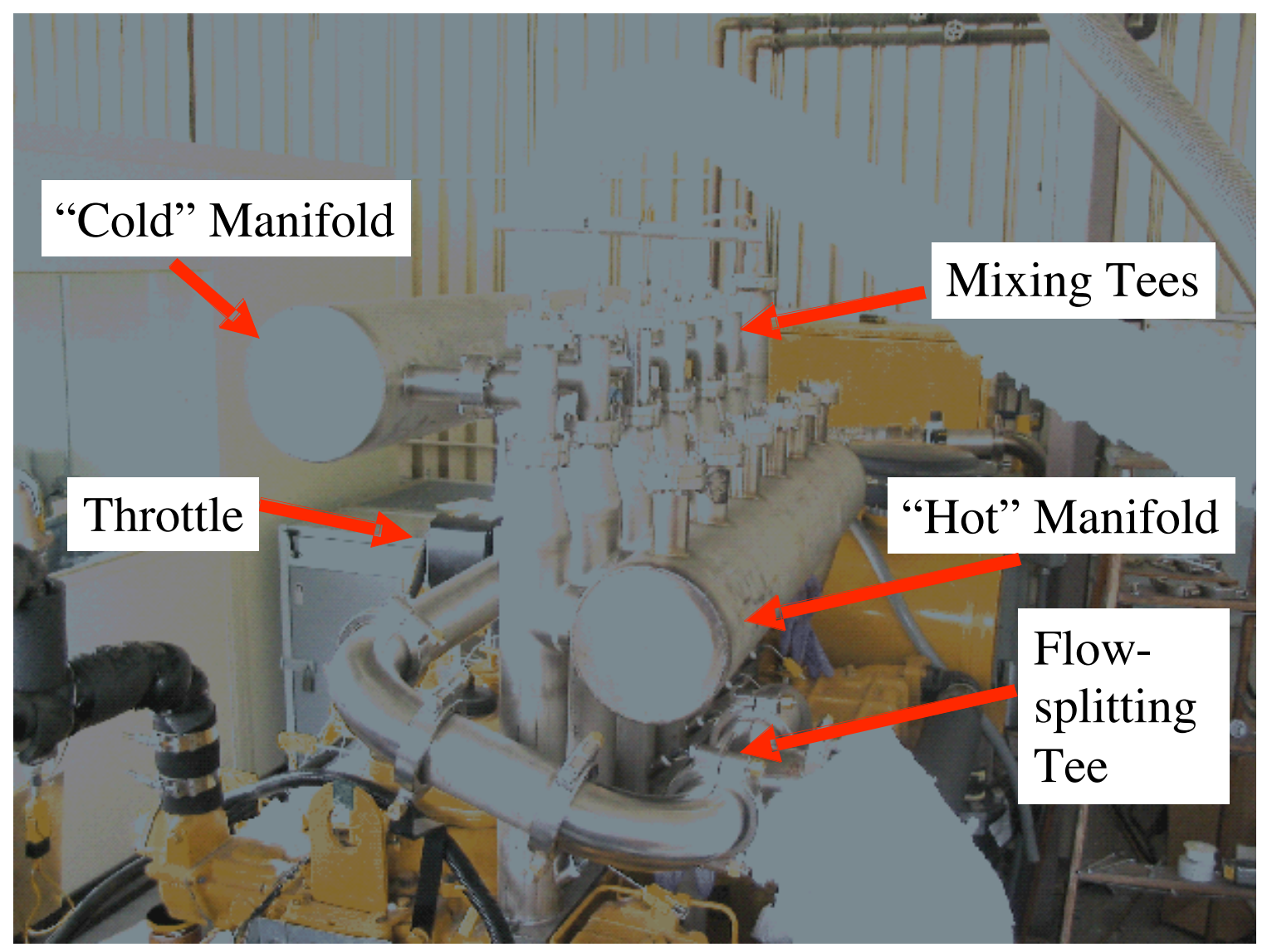

Figure 7. Picture of the cylinder by cylinder temperature control. 


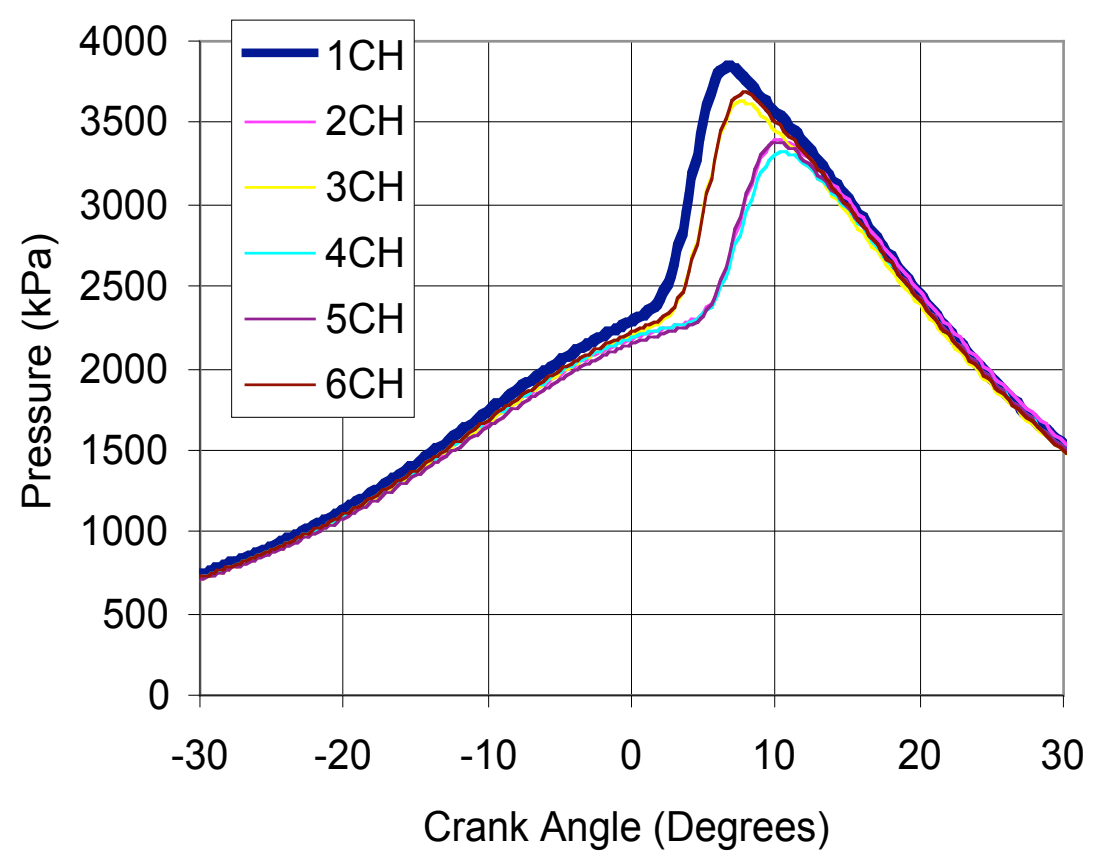

(a)

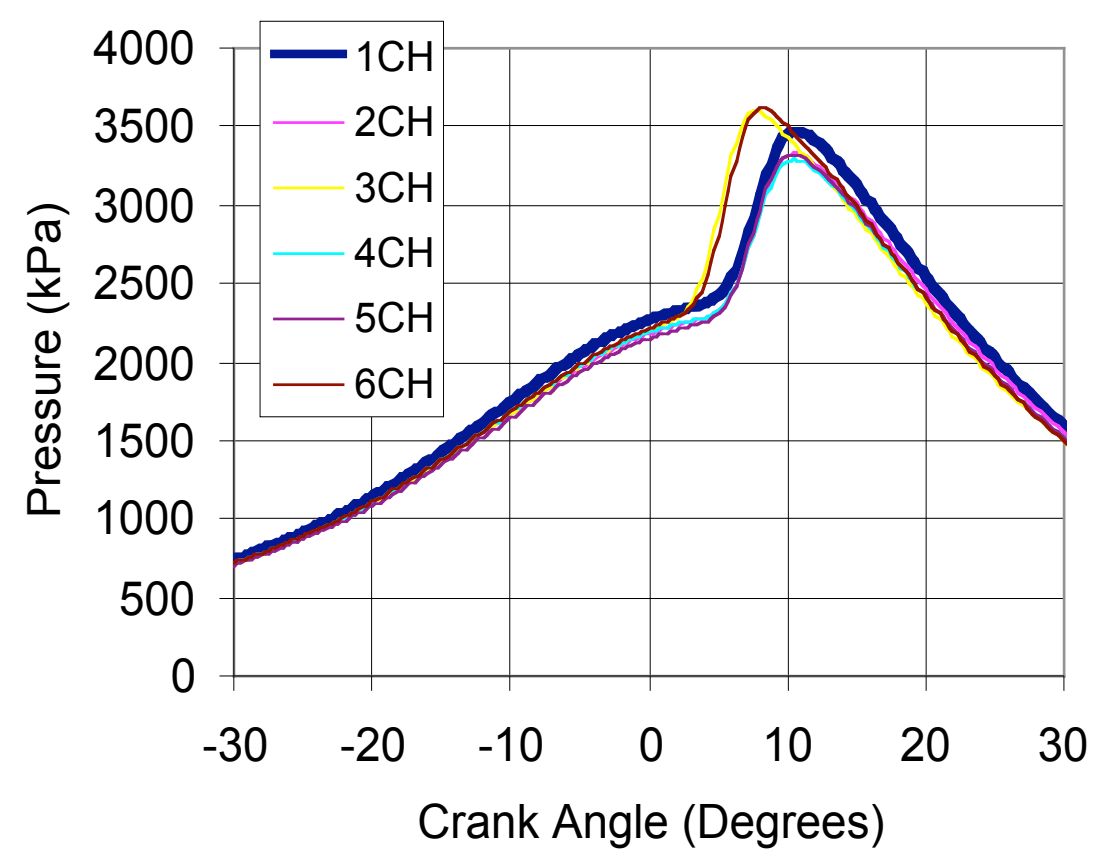

(b)

Figure 8. Pressure traces for 6-cylinder engine operation (a) with no-cylinder timing adjustment, and (b) with adjustment of timing on cylinder one by adjustment of hot air and cold air flow with the mixing tee assembly. 


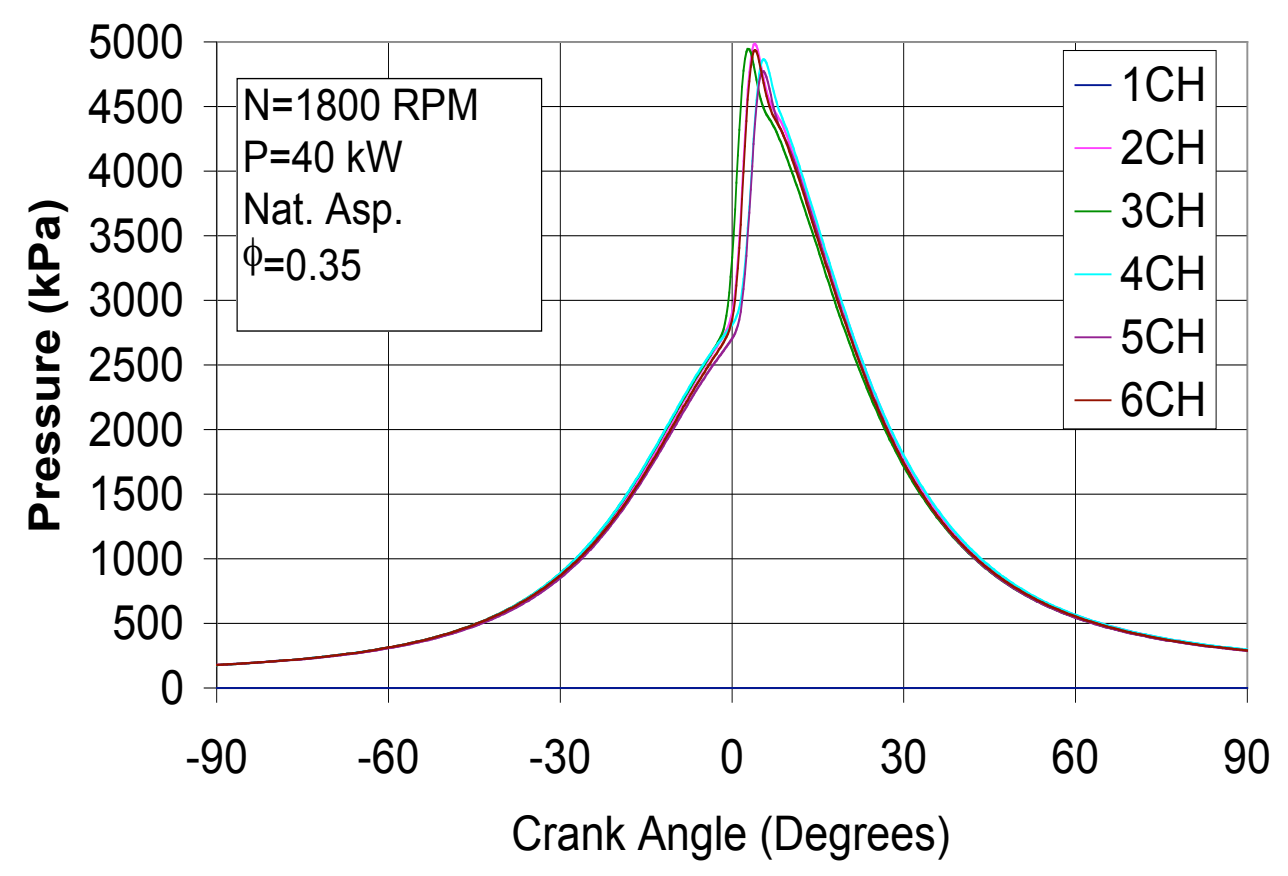

Figure 9. Pressure traces for balanced engine operation of the 6-cylinder engine. 